\title{
Measuring the Resilience of Indonesian Communities to Disaster
}

\section{Yulinda Erma Suryani, Dwi Wahyuni Uningowati}

\author{
Universitas Widya Dharma Klaten \\ yulinda@unwidha.id
}

\section{Article History \\ accepted 31/08/2020}

\begin{abstract}
In psychology, there are several concepts regarding toughness, namely: resilience, hardiness and grit. The concept of resilience and its measuring instruments are the result of adaptation of theories from abroad that cannot be directly applied in Indonesia, because there are fundamental differences in the life order of Indonesian society, so it is necessary to develop tools or instruments to measure the resilience of Indonesian society. This research was conducted using a qualitative approach. The data collection method used was literature study, in the form of primary literature and secondary literature. The data analysis method used is content analysis. The concepts of resilience, hardiness, and grit cannot be applied directly in Indonesia, because there are fundamental differences in the life order of Indonesian society. There are two things that must be considered in drafting the resilience concept of Indonesian society, namely the issue of specific long-term goals and the issue of focus.
\end{abstract}

Keywords: Resilience, Hardiness, Grit

\section{Abstrak}

Dalam psikologi ada beberapa konsep mengenai ketangguhan yaitu: resilience, hardiness dan grit. Konsep ketangguhan beserta alat ukurnya merupahan hasil adaptasi dari teori dari luar negeri yang tidak dapat langsung diterapkan di Indonesia, karena ada perbedaan yang mendasar dalam tata kehidupan masyarakat Indonesia sehingga perlu dikembangkan alat atau instrumen untuk mengukur ketangguhan masyarakat Indonesia. Penelitian ini dilakukan dengan menggunakan pendekatan kualitatif. Metode pengumpulan data yang digunakan adalah menggunakan studi literatur, berupa literatur primer dan literatur sekunder. Metode analisis data ayang digunakan adalah analisis isi (content analysis). Konsep resiliensi, hardiness, dan grit tidak bisa diterapkan secara langsung di Indonesia, karena ada perbedaan yang mendasar dalam tata kehidupan masyarakat Indonesia. Ada dua hal yang harus dipertimbangkan dalam menyusun konsep ketangguhan masyarakat Indonesia yaitu isu tentang tujuan jangka panjang yang spesifik dan isu tentang fokus.

Kata kunci: Resiliensi, Hardinnes. Grit

Social, Humanities, and Education Studies (SHEs): Conference Series https://jurnal.uns.ac.id/shes

p-ISSN 2620-9284

e-ISSN 2620-9292 


\section{PENDAHULUAN}

Bencana adalah peristiwa atau rangkaian peristiwa yang disebabkan faktor alam, faktor nonalam, dan/atau faktor manusia yang mengancam dan mengganggu kehidupan dan penghidupan masyarakat yang menyebabkan timbulnya korban jiwa, kerusakan lingkungan, kerugian ekonomi, kerugian sosial dan/atau dampak psikologis serta menimbulkan gangguan terhadap tata kehidupan dan penghidupan masyarakat yang melampaui kemampuan masyarakat terdampak (BNPB, 2007). Bencana Alam adalah bencana yang diakibatkan oleh peristiwa atau serangkaian peristiwa yang disebabkan oleh alam antara lain berupa gempa bumi, likuifaksi, tsunami, erupsi gunung api, gerakan tanah, banjir, banjir bandang, rob, iklim ekstrim, angin topan, cuaca ekstrim, gelombang laut berbahaya, abrasi, benda angkasa alam, dan kekeringan. Bencana Nonalam adalah bencana yang diakibatkan oleh peristiwa atau rangkaian peristiwa nonalam yang antara lain berupa gagal teknologi, epidemi, pandemi, kebakaran hutan, kebakaran lahan, kebakaran kawasan permukiman, hama, kecelakaan transportasi, dan wabah penyakit. Bencana Sosial adalah bencana yang diakibatkan oleh peristiwa atau serangkaian peristiwa yang diakibatkan oleh manusia yang berupa konflik sosial antarkelompok atau antarkomunitas masyarakat, kerusuhan sosial, dan tindakan terror. Bencana tersebut sering kali menimbulkan kerugian materil maupun non-materil di tengah masyarakat.

Untuk mencegah timbulnya kerugian yang masif, upaya yang dilakukan adalah membangun ketangguhan masyarakat terhadap bencana. Ada banyak program yang telah dicanangkan oleh pemerintah untuk membangun ketangguhan masyarakat terhadap bencana diantaranya: Kampung siaga bencana (Kementrian Sosial), desa siaga (Kementrian Kesehatan), pesisir tangguh bencana (Kementrian Kelautan), desa/kelurahan tangguh bencana dan keluarga tangguh bencana (BNPB).

Program kampung siaga Kementerian Sosial RI tidak hanya sebagai pembuat kebijakan akan tetapi juga melaksanakan pembentukan kelembagaan kampung siaga bencana. Tujuan dari kampung siaga bencana adalah memberikan pemahaman dan kesadaran masyarakat, membentuk jejaring dan memperkuat interaksi sosial, mengorganisasikan, menjamin kesinambungan, mengoptimalkan potensi dan sumber daya.

Desa siaga merupakan strategi baru pembangunan kesehatan, yang lahir sebagai respon pemerintah terhadap masalah kesehatan di Indonesia yang tak kunjung selesai. Ditambah lagi dengan bencana alam yang sering menimpa bangsa Indonesia seperti gunung meletus, tsunami, gempa bumi, banjir, tanah longsor dan kecelakaan massal menambah kompleksitas masalah kesehatan di Indonesia. Konsep desa siaga adalah membangun suatu sistem di suatu desa yang bertanggung jawab memelihara kesehatan masyarakat itu sendiri, di bawah bimbingan dan interaksi dengan seorang bidan dan 2 orang kader desa. Program ini melibatkan berbagai pengurus desa untuk mendorong peran serta masyarakat dalam program kesehatan seperti imunisasi dan posyandu (Depkes, 2009).

Program desa pesisir tangguh (PDPT) dari Kementrian Kelatuan secara umum bertujuan untuk meningkatkan kesejahteraan masyarakat pesisir dan ketangguhan desa. Secara khusus PDPT ini bertujuan untuk meningkatkan pelajaranan prasarana \& sarana sosial ekonomi, meningkatkan kualitas lingkungan hidup, meningkatkan kapasitas kelembagaan masyrakat dan pemerintah daerah dalam proses keputusan secara partisipatif, meningkatkan kesiapsiagaan terhadap bencana dan perubahan iklim.

Desa/kelurahan tangguh bencana adalah program BNPB agar desa memiliki kemampuan mandiri untuk beradaptasi dan menghadapi potensi ancaman bencana, serta memulihkan diri dengan segera dari dampak-dampak bencana yanag merugikan. 
Membangun ketangguhan masyarakat terhadap becana tentu saja tidak lepas dari konsep ketangguhan pribadi. Ketangguhan pribadi hanya salah satu bentuk ketangguhan karena katangguhan terkait konteks, sehingga akan muncul monep mengenai ketangguhan relasi, ketangguhan berkelompok, ketangguhan keluarga, ketangguhan masyarakat, ketangguhan dalam bekerja.

Tangguh secara etimologi berarti sukar dilakahkan, kuat (pendirian dan sebagainya), andal, tabah dan tahan (menderita dan sebagainya), dan kukuh (Alwi,2007). Ada istilah lain yang hampir sama dengan ketangguhan yaitu kegigihan. Kegigihan (perseverance) adalah suatu upaya yang terus menerus tanpa lelah berjuang dalam menghadapi rintangan namun dalam istilah kegigihan tidak terkandung hasrat (passion) atau konsistensi minat. Banyak orang yang selalu gigih dalam memperjuangkan keinginannya tetapi gagal mewujudkan hasratnya karena kurang fokus. Kata kunci dari tangguh adalah determinasi diri, yang berarti ada suatu arah yang dituju di masa depan dan tidak hanya sekedar kuat dan handal dalam menghadapi goncangan atau kegagalan. Orang menjadi tangguh karena ia mempunyai arah yang jelas yang ingin dituju. Orientasinya bukan bertahan di masa kini, tetapi bertahan di masa kini untuk meraih tujuan di masa depan yang jelas.

Bagaimana dengan ketangguhan masyarakat Indonesia terhadap bencana? Bagaimana kita dapat mengukurnya? Apakah ada alat ukurnya? Jawaban atas pertanyaan-pertanyaan tersebut akan dijawab melalui penelitian ini. Tujuan penelitian ini adalah untuk menyusun konsep ketangguhan dalam perspektif psikologi. Hasil penelitian ini sebagai bahan untuk menyusun alat ukur ketangguhan masyarakat Indonesia terhadap bencana.

\section{METODE}

Penelitian ini dilakukan dengan menggunakan pendekatan kualitatif. Metode pengumpulan data yang digunakan adalah menggunakan studi literatur, berupa literatur primer dan literatur sekunder. Metode analisis data yang digunakan adalah analisis isi (content analysis).

\section{HASIL DAN PEMBAHASAN}

Dalam psikologi dikenal beberapa konsep yang mempunyai makna yang hampir sama dengan konsep ketangguhan yaitu:

\section{Resiliensi}

Resiliensi pertama kali dikenalkan pada 1950-an oleh Blok dengan nama ego-resiliency (ER), yang diartikan sebagai kemampuan umum yang melibatkan kemampuan penyesuaian diri yang tinggi dan luwes saat dihadapkan pada tekanan internal maupun eksternal, Farkas \& Orosz (2015). Resiliensi akan membuat seseorang dapat menyesuaikan diri dan bertahan dari tekanan yang muncul dari berbagai kejutan dalam hidupnya. Namun resiliensi tidak menjamin seseorang terhindar dari tekanan dan kesulitan.

Individu yang memiliki resiliensi yang tinggi akan cenderung easygoing, mudah bersosialisasi, memiliki keterampilan berpikir yang baik termasuk keterampilan sosial dan kemampuan menilai sesuatu, memiliki orang di sekitar yang mendukung, memiliki satu atau lebih bakat, yakin pada diri sendiri dan percaya pada kemampuannya dalam mengambil keputusan serta memiliki spritualitas dan religiusitas. Kebajikan (virtue) dan kekuatan (strength) sebagai dasar untuk memiliki resiliensi (Chung, 2008).

Resiliensi merupakan proses adaptasi dengan perubahan yang terjadi dalam kehidupan. Resiliensi dapat membuat seseorang bangkit dari krisis yang dihadapinya. Kebangkitan dari masa krisis akan berdampak pada pengembangan diri yang lebih baik. Seseorang akan bertumbuh menjadi pribadi yang kuat dan percaya diri terhadap kehidupannya. Resiliensi juga memberikan ketenangan dan 
dukungan dalam bersikap di masa krisis (American Psychological Association (APA), 2020).

Ada banyak alat ukur yang bisa digunakan untuk resiliensi, salah satu diantaranya adalah The Connor-Davidson Resilience Scale (CD-RISC) yang dikembangkan oleh Connor dan Davidson (2003). Alat ukur CD-RISC terdiri dari 25 item yang dikembangkan berdasarkan berdasarkan lima aspek Resiliensi dari Connor dan Davidson, yaitu: (a). Personal competence, high standards, and tenacity, aspek ini merupakan faktor yang mendukung seorang untuk terus maju terhadap tujuan saat orang tersebut mengalami tekanan atau adversity; (b) Trust in one's instincts, tolerance of negative affect, and strengthening effects of stress, aspek ini berfokus pada ketenangan, keputusan dan ketepatan saat menghadapi stress; (c). Positive acceptance of change, and secure relationships, aspek ini berkaitan dengan adaptasi yang dimiliki seseorang; (d). Control, aspek ini berfokus pada kontrol dalam mencapai tujuan dan kemampuan untuk mendapatkan bantuan dari orang lain ataupun dukungan social; dan (e) Spiritual influences, aspek ini merupakan kepercayaan seseorang pada Tuhan atau nasib. Alat ukur ini menggunakan Skala Likert dengan menggunakan lima pilihan jawaban, mulai dari tidak benar sma sekali (0); jarang (1); kadang-kadang (2); sering (3); sangat sering (4) dengan kisaran skor 0-100. Semakin tinggi skor yang diperoleh subjek, maka semakin tinggi pula resiliensi subjek.

\begin{tabular}{ll}
\hline Item no. & \multicolumn{1}{c}{ Description } \\
\hline 1 & Able to adapt to change \\
2 & Close and secure relationships \\
3 & Sometimes fate or God can help \\
4 & Can deal with whatever comes \\
5 & Past sucess gives confidence for new challenge \\
6 & See the humorous side of things \\
7 & Coping with stress strengthens \\
8 & Tend to bounce back after illness or hardship \\
9 & Things happen for a reason \\
10 & Best effort no matter what \\
11 & You can achieve your goals \\
12 & When things look hopeless, I don't give up \\
13 & Know where to turn for help \\
14 & Under pressure, focus and think clearly \\
15 & Prefer to take the lead in problem solving \\
16 & Not easily discouraged by failure \\
17 & Think of self as strong person \\
18 & Make unpopular or difficult decisions \\
19 & Can handle unpleasant feelings \\
20 & Have to act on a hunch \\
21 & Strong sense of purpose \\
22 & In control of your life \\
23 & 1 like challenges \\
24 & You work to attain your goals \\
25 & Pride in your achievements \\
\hline
\end{tabular}

\section{Gambar 1. The Connor-Davidson Resilience Scale (CD-RISC)}

\section{Hardiness}

Studi tentang Hardiness pertama kali dilakukan oleh Kobasa (1981). Hardiness adalah suatu konstalasi karakteristik kepribadian yang membuat individu menjadi lebih kuat, tahan, stabil dan optimis dalam menghadapi stress dan mengurangi efek negatif yang dihadapi (Kobasa,1981). Manusia selalu mencari bagaimana cara terbaik menghadapi, memanfaatkan, dan membentuk kehidupannya. Dalam menghadapi kenyataan, sebagian orang gagal, sebagian lainnya berhasil. Namun demikian manusia tetap dapat bangkit menghadapi 
tantangan dan mengubah peristiwa yang menekan menjadi kemungkinan dan kesempatan untuk pertumbuhan dan kebermanfaatan pribadi. Salah satu alat ukur yang bisa digunakan untuk mengukur hardiness adalah Occupational Hardiness Questionnaire yang dikembangkan oleh Jimenez, dkk (2014) terdiri dari 15 item berdasarkan 3 aspek dari Kobas (1981), yaitu: Komitmen, kontrol, dan tantangan.

Orang yang berkomitmen tinggi ditandai dengan dia tidak hanya sekedar tahu mengenai keterlibatan 'apa' seseorang pada suatu aktivitas, tetapi juga 'mengapa' dia memilih terlibat dalam aktivitas tersebut. Komitmen lebih dari sekedar harga diri dan kompetensi karena didasarkan pada rasa komunitas, yaitu bahwa seseorang adalah mahluk sosial, hidup bersama dengan orang lain. Orang yang berkomitmen mendapatkan manfaat, baik pengetahuan yang dapat mereka berikan kepada orang lain dalam waktu-waktu yang menekan maupun rasa bahwa orang lain turut andil dalam kemampuan mereka untuk tidak menyerah ketika menghadapi tekanan-tekanan yang besar. Orang yang berkomitmen memiliki keterampilan dan hasrat yang besar untuk mengatasi tekanan hidup (Kobasa, 1981). Kontrol terlihat dari tanda-tanda di dalam diri seseorang. Hal ini ditandai oleh kepemilikan sejumlah strategi pengatasan stres (coping repertoire), yaitu bermacam-macam respon behavioral efektif terhadap peristwa hidup yang menekan. Seseorang dengan kontrol merasa mampu bertindak efektif pada dirinya sendiri. Kontrol mengakibatkan seseorang mencari penjelasan mengapa seseorang mengalami peristiwa yang menekan, ia tidak hanya menyalahkan orang lain atau takdir. Hal ini dilakukan karena rasa tanggungjawab personal yang tinggi. Metode normatif kehidupan adalah perubahan, bukan stabilitas. Di dalam perubahan terkandung sebuah tantangan. Seseorang yang menerima tantangan berusaha mengeksplorasi lingkungannya dan tahu ke mana harus menuju untuk mendapatkan bantuan mengatasi tekanan. Ciri yang dimiliki orang tersebut adalah keterbukaan atau fleksibilitas kognitif dan toleransi ambiguitas. Berikut ini item-item pada Occupational Hardiness Questionnaire

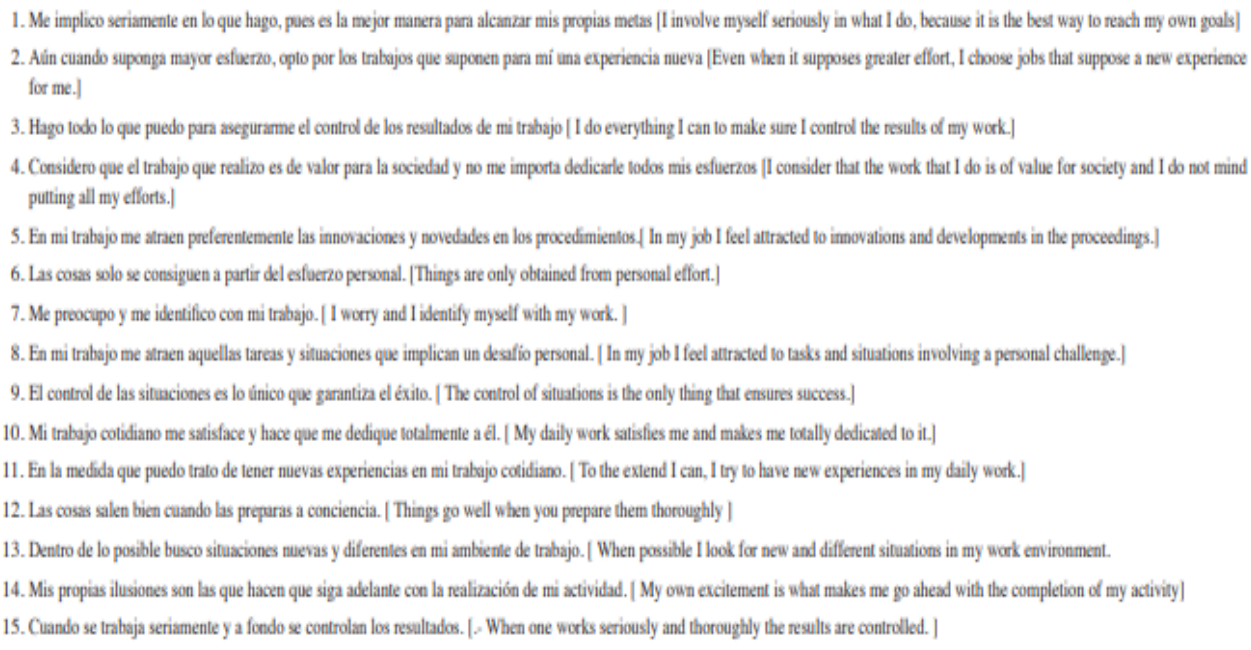

\section{Gambar 1. The Connor-Davidson Resilience Scale (CD-RISC)}

3. Grit

Dalam psikologi, grit merupakan sifat non-kognitif, didefenisiskan sebagai kegigihan dan hasrat untuk mencapai tujuan-tujuan jangka panjang. Orang dengan kegigihan dan hasrat mencapai tujuan tampak dari perilaku mereka bekerja sekuat tenaga (stenously) menghadapi tantangan, memelihara upaya dan minat sepanjang waktu meskipun meghadapi kegagalan, kesukaran dan ketiadaan kemajuan (pleateaus in progress). Mereka memahami pencapaian keberhasilan ibarat lari 
maraton dan kekhasan mereka berada pada stamina. Bagi orang lain kekecewaan, goncangan, dan kemungkinan kebosanan menjadi tanda waktu untuk mengubah jalan, merasakan kekalahan, dan bahkan menghapus harapan tetapi bagi orang yang gigih mereka tetap bertahan. Ketekunan dan konsisten terhadap minat dari seorang individu inilah yang disebut sebagai Grit (Duckworth,2007).

Konsep grit mirip dengan sifat conscientiouness dalam teroi kepribadian Big Five dan Need for achievement dari David McClelland. Conscientiouness adalah sifat menyeluruh dan detail (thorough), penuh kehati-hatian, dan waspada. Ciri khas grit adalah stamina, yang mencerminkan kapasitas memelihara baik upaya maupun minat pada rencana yang memakan waktu lama. Jika dibandingkan dengan need for achievement dr McClelland, keberadaan insentif (umpan balik positif) sangan berpengaruh. Individu dengan grit yang tinggi tetap mencapai tujuan walaupun tidak ada insentif atau umpan balik.

Setiap orang memiliki tingkat grit yang berbeda-beda. Salah satu faktor yang menentukan perbedaan tersebut adalah perbedaan pendekatan individu terhadap pengejaran kebahagiaan dalam hidup, apakah itu kesenangaan, aktivis hedonis, kebermaknaan dalam aktivitas yang memiliki tujuan altruis, atau keterlibatan dalam aktivitas yang menyerap perhatian (Von Culin dkk, 2014). Ada banyak faktor yang mempengaruhi tinggi rendahnya grit, menurut Duckworth dkk (2007) pada usia yang sama, semakin tinggi pendidikan orang dewasa, semakin tinggi gritnya. Ketika usia di kontrol, lulusan pascasarjana lebih tinggi gritnya dibandingkan kelompok pendidikan di bawahnya.

Menurut Duckworth dkk (2007) merupakan kecenderungan individu untuk mempertahankan ketekunan dan semangat untuk tujuan jangka panjang yang menantang, dimana setiap individu bertahan dengan hal-hal yang menjadi tujuan mereka dalam jangka waktu yang panjang sampai mereka mencapai tujuan tersebut. Di dalam Grit terdapat dua hal penting, yakni konsistensi minat (Passion) dan ketekunan usaha (Perseverance). Konsistensi minat diartikan sebagai seberapa konsisten usaha seseorang untuk menuju suatu arah, dan ketekunan usaha. Aspek ini berfokus pada minat dalam jangka waktu yang berlangsung lama atau konsistensi Konsistensi dapat tdilihat dari minat dan tujuan individu yang tidak mudah berubah, tidak mudah beralih kepada ide/minat/tujuan lain dan tetap fokus pada tujuan awal yang telah dibuat. Jadi konsisten minat dapat dilihat dari minat individu yang berlangsung dalam jangka waktu yang lama dan cenderung menetap. Ketekunan usaha (Perseverance) adalah seberapa keras seseorang berusaha untuk mencapai tujuan serta berapa lama seseorang dapat mempertahankan usaha. Ketekunan dalam berusaha ditunjukan melalui perilaku individu yang giat dalam bekerja keras, bertahan dalam menghadapi tantangan dan mampu berpegang teguh dengan pilihannya.

Alat ukur yang dapat digunakan dalam pengukuran grit adalah Grit Scale yang dikembangkan oleh Duckworth dkk (2007) yang terdiri dari 12 aitem, yang berupa alat ukur kuesioner(self report) berbentuk skala Likert. Pada tahun 2009 Duckworth \& Quinn mengembangkan kembali Grit Sale menjadi Grit Scale The Short (Grit-S) yang terdiri dari 8 aitem yang digunakan untuk mengukur grit pada anak-anak. Berikut ini aitem-aitem dari Grit Scale maupun Grit Scale The Short (Grit-S). 

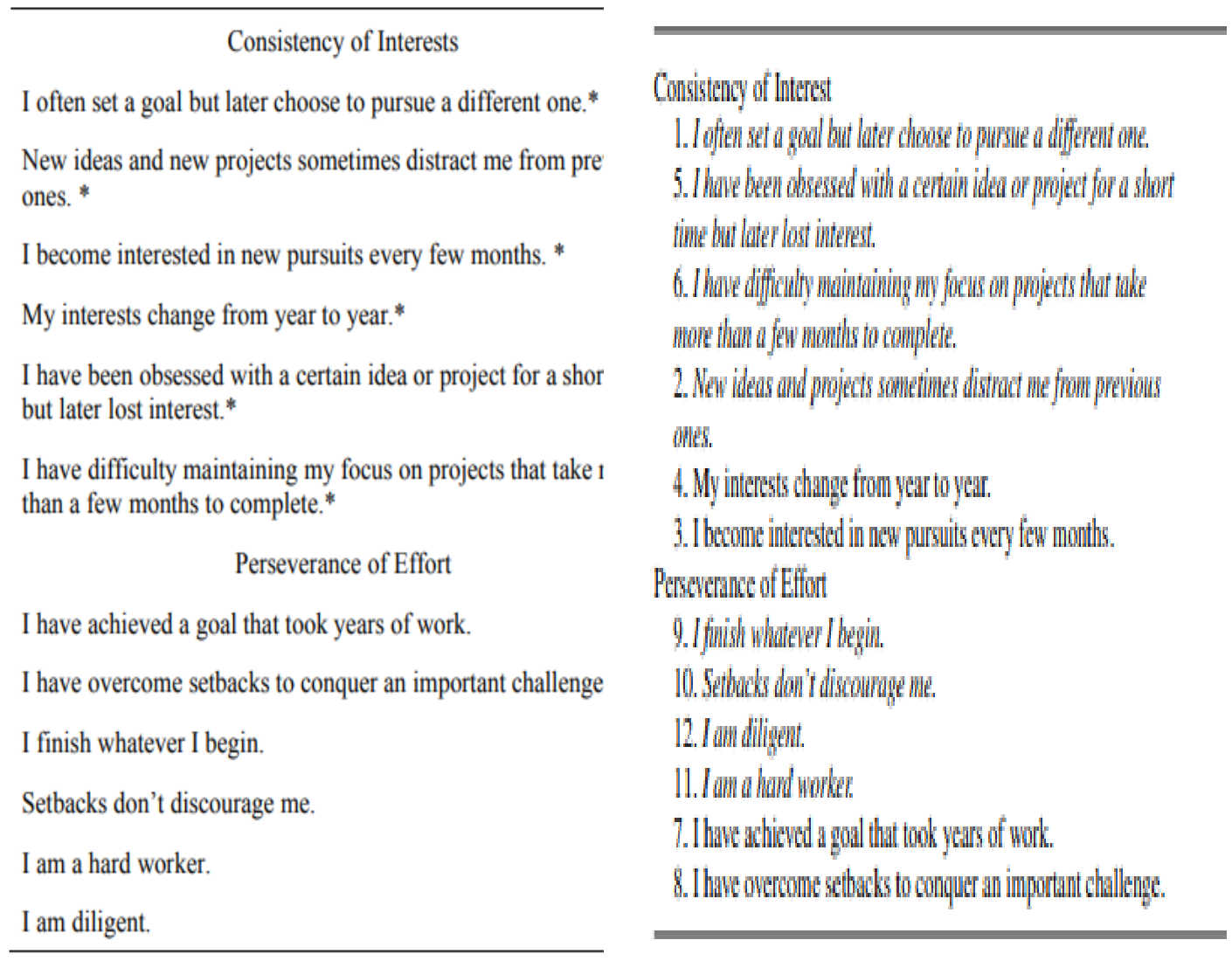

\section{Gambar 3. Grit Scale \& Grit Scale The Short (Grit-S)}

\section{SIMPULAN}

Resiliensi, Hardiness, Grit adalah konsep-konsep psikologi yang berkaitan dengan ketangguhan. Konsep -konsep tersebut tidak bisa diterapkan secara langsung di Indonesia, karena ada perbedaan yang mendasar dalam tata kehidupan masyarakat Indonesia. Ketangguhan sebenarnya hanyalah sarana atau proses untuk mencapai tujuan. Ketangguhan pribadi hanya salah satu bentuk ketangguhan karena ketangguhan terkait konstek sehingga akan muncul konsep mengenai ketangguhan relas, ketangguhan keluarga, dsb. Hal ini membutuhkan eksplorasi kembali terkait pamahaman katangguhan yang terkait konsteks sehingga memberi ruang konstruk secara teoritis.

Ada dua hal yang harus dipertimbangkan dalam menyusun konsep ketangguhan masyarakat Indonesia yaitu isu tentang tujuan jangka panjang yang spesifik dan isu tentang fokus. Resiliensi, Hardiness, Grit dapat digunakan untuk menyusun konsep ketangguhan masyarakat Indonesia terhadap bencana. Setelah konstruk teoritis terbentuk, maka dapat dikembangkan pula alat untuk mengukur ketangguhan masyarakat Indonesia terhadap bencana yang sesuai dengan karakteristik masyarakat Indonesia.

\section{DAFTAR PUSTAKA}

America Psychological Association. (2020, February 01). Building Your Resilience. Retrieved from https://www.apa.org/topics/resilience

Badan Nasional Penanggulangan Bencana. (2007). Undang-Undang No. 24 Tahun 2007 Tentang Penanggulangan Bencana 
Chung, H. F. (2008). Resiliency and character strengths among college students.ProQuest. (Unpublished doctoral dissertation). The University of Arizona, Tucson.

Duckworth, A.L, \& Quinn, P.D. (2009). Development and validation of the Short Grit Scale (GritS). Journal of Personality Assessment, 91, 166-174. https://globaled.gse.harvard.edu/files/geii/files/validation grit scale duckworth ip a m. figueroa-2.pdf

Duckworth, A.L., Peterson, C., Matthews, M.D., \& Kelly, D.R. (2007). Grit: Perseverance and passion for long-term goals. Journal of Personality and Social

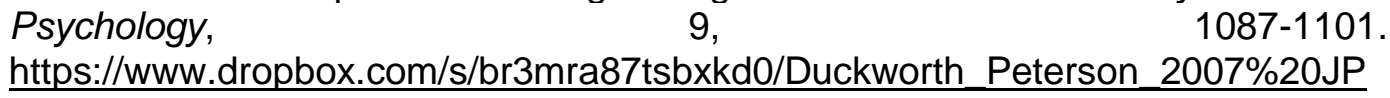
SP\%20.pdf?dl=0

Farkas, D., \& Orosz, G. (2015). Ego-resiliency reloaded: A three-component model of general resiliency. PLoS ONE. https://doi.org/10.1371/journal.pone.0120883

Habibullah. (2013) Kebijakan Penanggulangan Bencana Berbasis Komunitas: Kampung Siaga Bencana dan Desa/Kelurahan Tangguh Bencana. Sosio Informa; Kajian Permasalahan Sosial dan Kesejahteraan Sosial. Vol 18, No 2 (2013)

Diakses dari https://ejournal.kemsos.go.id/index.php/Sosioinforma/article/view/69/38

Helmi. A.F. (2016). Psikologi Untuk Indonesia Tangguh dan Bahagia. Manusia Indonesia Yang Tangguh. Yogyakarta: UGM Pres

Hendriani, W. (2018). Resiliensi Psikologis. 1rd ed. Jakarta Timur: Prenadamedia Group.

Jimenez, B M., Munoz, A, R., Garrosa, E., Donoso, L M B.(2014) Development and validation of the Occupational Hardiness Questionnaire. Psicothema 2014, Vol. 26, No. 2, 207-214. DOI: 10.7334 / psicothema2013.49

Kobas, S.C. (1981). The Hardy Personality: Toward a Social Psychology of Stress and Health. Dalam D.S.Sanders \& J. Suls.Sosial Psychology of Health and IIIness (pp.3-32). Nwe Jersey: Lawrence Erlbaum

Mulyani, N, S. (2011). Resiliensi Daya Tahan Menghadapi Trauma Kehidupan. Medan: USU Press.

Simatupang, A.R. (2019). Psikologi Terapan Bencana. Yogyakarta: Zahir publishing

Universitas Psikologi: https://www.universitaspsikologi.com/2020/01/teori-resiliensidan-pengertian-resilience.html

Von Culli, K.R., Tsukayama, E., \& Dockworth, A.L. (2014). Unpacking Grit: Motivasional Correlates of Perseverence and Passion for Long-Term Goal. The Journal of Positive Psychology, 9(4), 306-312. Http://dx.doi.org/10.1080/17439760.2014'898320

http://promkes.kemkes.go.id/pengertian-tujuan-indikator-dan-kegiatan-pokok-desasiaga 